\title{
AUTO RELATO DE SITUAÇÕES CONSTRANGEDORAS NO TRABALHO E ASSÉDIO MORAL NOS BANCÁRIOS: UMA FOTOGRAFIA
}

\author{
Regina Heloisa Maciel \\ Rosemary Cavalcante \\ Teresa Glaucia Rocha Matos \\ Universidade de Fortaleza, Fortaleza, Brasil \\ Suzineide Rodrigues \\ Sindicato dos Bancários de Pernambuco, Recife, Brasil
}

RESUMO: As definições existentes do assédio moral no trabalho, apesar de ainda não haver um consenso, apontam para a ocorrência de atos negativos ou situações constrangedoras no trabalho que perdurem por um certo período de tempo e frequiência e onde a vítima se sinta intimidada. O objetivo deste trabalho foi identificar e analisar a ocorrência de situações constrangedoras no trabalho, relatadas por bancários brasileiros. O método consistiu na aplicação de um questionário em 2609 bancários. 33,89\% da amostra relata ter sido exposta a pelo menos uma das situações constrangedoras apresentadas no questionário. Quando se considera o período de exposição de seis meses e freqüência semanal, $7,97 \%$ da amostra relata ter sido assediada. Além disso, as mulheres e o grupo de homo ou bissexuais relatam terem sido assediadas com maior frequiência. Esses resultados mostram que os bancários brasileiros estão expostos ao assédio moral com uma taxa similar às encontradas em estudos europeus.

PALAVRAS-CHAVE: Assédio moral no trabalho; bancários; gênero; orientação sexual.

\section{SELF REPORT OF NEGATIVE ACTS AND BULLYING IN WORK SITUATIONS AMONG BANK EMPLOYEES: A PHOTOGRAPHY}

\begin{abstract}
The actual definition of bullying at work, although not a consensus, focuses on the occurrence of negative acts or constraining situations in the workplace, that lasts for a certain period of time; occurring on a weekly basis; and the victim feels intimidated. The objective of this work was to identify and analyze the occurrence of constraining situations, self-reported by Brazilian bank employees. A questionnaire was applied in 2609 bank employees. 33,89\% of the sample reported at least one of the constraining situations presented in the questionnaire. When a period of exposition of six months and weekly frequency are taken into consideration, 7,97\% of the sample reported bullying. Besides, the women and the homo or bisexual group reported bullying with a higher frequency than the other groups. Those results show that the Brazilian bank employees are exposed to bullying at work with a frequency similar to those found in European studies.
\end{abstract}

KEYWORDS: Bullying in work situations, bank employees, gender, sexual orientation.

\section{O que é Assédio Moral no Trabalho}

O tema assédio moral no trabalho, também conhecido como violência moral ou psicoterrorismo no trabalho, tem sido recorrente nos últimos anos, aparecendo na mídia em geral, nas reivindicações de várias categorias de trabalhadores e na literatura especializada. O mobbing ou bullying no contexto laboral - como o fenômeno é conhecido na Europa - foi primeiramente estudado nos países escandinavos (Einarsen \& Skogstad, 1996; Leymann \& Gustafsson, 1996), apesar de ter sido descrito anteriormente como harrassment por Brodsky, em 1976 (citado em Einarsen, 2005). No Brasil, o assunto não tem merecido tanta atenção dos pesquisadores, embora haja um crescente interesse pelo tema. Nos países europeus existem vários grupos de pesquisas sobre o assunto, financiados pelos governos e Comunidade Européia (Quine, 1999).
No site Mobbing.nu (Mobbing.Nu, 2006), são descritas várias leis nacionais que dispõe sobre o assédio moral, assédio sexual e assédio moral no trabalho, incluindo as legislações da Espanha, Argentina, Austrália, Bélgica, Brasil, Canadá, França, Alemanha, Itália, Luxemburgo, Suíça, Suécia, Inglaterra, Uruguai e Estados Unidos. A legislação brasileira está restrita a algumas organizações da administração pública de alguns estados, apesar de alguns projetos de lei estarem em discussão (Barreto, 2003a). Ao contrário, Buskpan (2004), aponta as discrepâncias na lei francesa quanto à menor proteção dos trabalhadores de empresas públicas em relação às privadas.

Uma primeira questão relacionada ao tema é a falta de consenso sobre uma definição precisa sobre o que é o assédio moral no trabalho e a discussão sobre a pertinência e validade dos vários instrumentos e métodos utilizados 
para sua avaliação, incluindo as significações dos diferentes termos utilizados para descrever o fenômeno (Cowie, Naylor, Rivers, Smith \& Pereira, 2002).

O Comitê Nacional inglês sobre o assédio (Bullying, 2006) e Leymann (2006) fazem uma diferenciação entre os termos mobbing e bullying. Segundo esses autores, o termo mobbing deveria ser reservado para caracterizar o assédio moral que ocorre no trabalho, pois esse tipo de assédio envolve relações sutis entre o assediador e o grupo ou equipe de trabalho e comportamentos sofisticados tais como o isolamento da vítima, por exemplo, e raramente violência física. Em contraposição, o termo bullying estaria mais relacionado a agressões físicas ou ameaças, caracterizando situações de assédio entre escolares e crianças, como nos estudos de Crothers e Levinson (2004), Nansel et al. (2001) e Natvig, Albrektsen e Qvarnstrom (2001). Na literatura nacional, encontramos com maior freqüência o termo assédio moral no trabalho, mas existem alguns autores que utilizam o termo mais geral "violência" ou até mesmo "psicoterrorismo" no trabalho.

A força-tarefa inglesa, estabelecida com o intuito de prevenir o assédio moral no trabalho (Task Force on Prevention of Workplace Bullying), em seu relatório de 2001 (Health and Safety Authority [Hsa], 2001) define o assédio moral no trabalho como a repetição de comportamentos inadequados, diretos ou indiretos, verbais, físicos ou de outra ordem, conduzidos por uma ou mais pessoas contra um outro ou outros, no local de trabalho e/ou no exercício de sua função, que podem ser razoavelmente percebidos como prejudicando os direitos individuais de dignidade no trabalho. Um acidente isolado dos comportamentos descritos na definição pode ser considerado uma afronta à dignidade no trabalho, mas uma única instância não é considerada assédio.

A tendência geral é considerar o assédio moral como a ocorrência de atos repetitivos e duradouros que implicam em um desequilíbrio das relações de poder entre a(s) vítima(s) e o(s) algoz(es) e inclui um elemento de subjetividade por parte da vítima em termos de como ela percebe esses atos e seus efeitos (Coyne, Craig \& Chong, 2004).

Barreto (2003a) define o assédio moral no trabalho como toda exposição prolongada e repetitiva a situações humilhantes e vexatórias no ambiente de trabalho. Essas humilhações se caracterizam por relações hierárquicas desumanas e autoritárias, onde a vítima é hostilizada e ridicularizada diante dos colegas e isolada do grupo.

O assédio moral não é um conceito novo e acontece em outras situações, além do trabalho, se inserindo no tópico mais geral dos valores morais e éticos das sociedades atuais e da violência nas relações sociais. Sennett (2006) discute a cultura do que ele denomina de "novo capitalismo", pontuando o espaço social criado por essa cultura no seio das organizações. Enfatiza que esse espaço é constituído de individualismo, incerteza e falta de responsabilidade nas relações sociais, trazendo, portanto, os determinantes da violência moral no trabalho. Fonseca Filho (2006), Monteiro, Espírito Santo e Bonacina (2005), Rego (2002) e Zylbersztajn (2002), discutem a ética nas organizações atuais, concluindo que as relações sociais internas são dependentes dos valores morais e códigos de ética vigentes na cultura da organização, determinados, por sua vez, pela ordem econômica e social mais ampla. Dada a complexidade dessas relações, não se pretende neste trabalho esgotar o tema, mas fornecer uma fotografia do assédio moral em uma amostra de bancários brasileiros e uma comparação com os dados sobre o fenômeno existentes na literatura.

Beswick, Gore e Palferman (2006), discutindo a controvérsia sobre o que é o assédio moral no trabalho e sua avaliação, pontuam as três principais áreas de debate: (a) a questão da objetividade ou subjetividade do assédio; (b) a questão da intencionalidade e (c) a categorização do assédio em pessoal ou organizacional. Ë claro que as três áreas de debate se relacionam e, além disso, como apontado por Liefooghe (2004), o estudo do assédio moral está em maturação e tem recebido diferentes contribuições de várias abordagens teóricas, importantes para a sua compreensão. No entanto, a multiplicidade de definições, de certa forma, compromete a comparação entre os diferentes resultados empíricos encontrados, principalmente no que se refere às taxas de prevalência do fenômeno.

Beswick et al. (2006) dividem o assédio moral no trabalho em duas grandes categorias: o pessoal, ligado às questões das relações interpessoais, tais como preconceitos e discriminações e o da organização do trabalho, ligado especificamente às questões do contexto, processo e gestão do trabalho. Mas como pontua Bjorkqvist (2001) a distinção entre os dois não é fácil de ser feita.

Utilizando-se de análises fatoriais e meta-análises dos estudos sobre o assédio, Dick e Rayner (2004) e Olafsson e Johannsdottir (2004) dividem o assédio moral no trabalho em quatro categorias, segundo a característica do comportamento negativo perpetrado: ataques à tarefa (reter informação, monitoramento excessivo, exigência de tarefas impossíveis e exigência de tarefas sem importância); ataques pessoais (comentários depreciativos, críticas persistentes, humilhações públicas, rumores maliciosos); isolamento (ser ignorado pelos outros, ser separado dos outros); e ataques verbais (gritos, abuso verbal, ameaças físicas).

A maioria dos estudos sobre a prevalência do assédio moral no trabalho se vale de relatos subjetivos, autorelatos, por parte das vítimas. Einarsen e pesquisadores utilizam um método que privilegia, inicialmente, o senti- 
mento da vítima sobre ter ou ter se sentido assediado e, em um segundo momento, de uma lista de comportamentos negativos (NAQ) (Einarsen \& Hoel, 2001). Leymann e pesquisadores medem o assédio também por meio de autorelatos a partir de uma lista de comportamentos ou situações constrangedoras (Inventário de Leymann de Psicoterrorismo no Trabalho - LIPT). As listas de comportamentos negativos dos dois instrumentos apresentam situações constrangedoras ou comportamentos negativos bastante similares. Além desses aspectos, os métodos procuram especificar a duração e a freqüência da vivência dessas situações. Em geral, uma pessoa é considerada assediada se teve um sentimento de constrangimento frente a um ou mais comportamentos perpetrados por uma ou mais pessoas no trabalho, pelo menos uma vez durante seis meses, repetido semanalmente. Os trabalhos de Matthiesen e Einarsen (2001), Mikkelsen e Einarsen (2001), Quine (1999, 2002), Zapf (1999), entre outros, são estudos sobre a prevalência do assédio em diferentes amostras de trabalhadores, utilizando os questionários com auto-relatos de situações constrangedoras ou comportamentos negativos.

Há ainda estudos em que são utilizados métodos qualitativos ou quanti-qualitativos, tais como grupos focais, entrevistas e estudos de caso como, por exemplo, Barreto (2003b), Bolino e Turnley (2003), Coyne et al. (2004), Lewis (2004), Liefooghe e Olafsson (1999), Salin (2005), entre outros.

Apesar das controvérsias sobre a definição e métodos de pesquisa no campo do assédio moral no trabalho, não existem dúvidas quanto às conseqüências provocadas pela exposição ao assédio moral no trabalho. As principais conseqüências são: depressão, ansiedade, sociofobia, ataques de pânico, baixa auto-estima, desordens psicossomáticas tais como insônia, melancolia, apatia, falta de concentração sudorese, tremores e outros sintomas comportamentais, que atestam para a importância de se estudar a prevalência e principais determinantes do fenômeno (Bjorkqvist, 2001; Hansen et al., 2006; Hoel, Sparks \& Cooper, 2001a; Hoel, Faragher \& Cooper, 2004; Matthiesen \& Einarsen, 2004; Tehrani, 2004).

\section{Prevalência}

As primeiras pesquisas realizadas na Escandinávia revelaram que aproximadamente 3 a $4 \%$ da população de trabalhadores é freqüentemente assediada no trabalho (Einarsen, Bjorn \& Matthiesen, 1994; Leymann, 1996). Na Inglaterra e na Finlândia, as taxas de incidência chegam a cerca de 10\% (Hoel, Cooper \& Faraguer, 2001b; Vartia, 1996). O estudo epidemiológico realizado por Leymann (1996) encontrou uma incidência de 120.000 novos casos a cada ano. Levando-se em consideração que a vida laboral das pessoas pode se estender a 30 anos, calcula-se que 1 de cada 4 trabalhadores corre o risco de sofrer violência moral em algum momento de sua trajetória profissional, com a duração de pelo menos seis meses.

A Organização Internacional do Trabalho (OIT) divulgou um estudo realizado nos países da União Européia, denunciando que as experiências de violência nos locais de trabalho apontam para a globalização do problema, transcendendo as fronteiras nacionais, ambientes de trabalho e grupos profissionais (OIT, 1998). No III Inquérito Europeu sobre Condições de Trabalho realizado em 2000, envolvendo 21500 trabalhadores de 15 países, encontrou-se que $2 \%$ estavam sujeitos à violência física exercida por superiores e colegas de trabalho, $4 \%$ violência física de clientes ou outras pessoas com quem se tem contato no trabalho, $2 \%$ foram objeto de assédio sexual e 9\% sofreram ações de intimidação (situações constrangedoras) (Paoli \& Merllié, 2001). Em uma revisão mais recente sobre o assunto, Einarsen (2005) estima que a prevalência do assédio moral nos trabalhadores europeus se situa entre 5 e $10 \%$.

No Brasil, Barreto (2003b) realizou uma pesquisa com 2072 trabalhadores de 97 empresas dos setores químico, farmacêutico, plástico e similares em São Paulo. Utilizando uma metodologia qualitativa, a autora estimou que $42 \%$ dos trabalhadores apresentavam histórias de humilhações e constrangimentos, o que evidencia o impacto do assédio moral nas organizações brasileiras.

\section{Antecedentes do Assédio Moral no Trabalho na Categoria Bancária}

No que se refere aos antecedentes organizacionais do assédio moral, há um consenso de que estes se originam de condições de trabalho que levam ao estresse, tais como a pressão pela produção, gerenciamento do trabalho através de metas e objetivos e outros aspectos geralmente relacionados ao processo de reestruturação produtiva e a introdução de novas tecnologias de gestão, além de possuírem um forte componente cultural (Einarsen, 2005; Liefooghe \& Davey, 2001; Salin, 2005; Zapf, 1999, entre outros).

A categoria bancária tem sido alvo das mudanças decorrentes da reestruturação produtiva que, na categoria, teve início durante os anos de 1980. Essas mudanças transformaram o trabalho e o contexto do trabalho bancário, levando ao aparecimento de queixas de assédio moral e a consequiências mais sérias na saúde de alguns trabalhadores, tais como depressão e suicídio. O trabalhador bancário da atualidade tem jornadas de trabalho mais longas; metas a serem cumpridas; pressão pela produção e controle estrito sobre os tempos de trabalho, entre outras modificações na organização do trabalho. O bancário vive uma transformação que o coloca frente a frente às novas formas de organização do trabalho e sofre as consequiên- 
cias disto: um maior número de afastamentos do trabalho por LER (Lesões por Esforços Repetitivos), estresse decorrente do trabalho e sofrimento mental (Grisci, 2002; Grisci \& Bessi, 2004; Laranjeira, 1997, 2001; Lima \& Maciel, 2001; Maciel, 2000a, 2002b; Segnini, 1999).

Diante desse quadro, pode-se supor que a prevalência do assédio moral no trabalho na categoria bancária seja elevada. No entanto, até o momento não existem dados sobre a ocorrência do assédio moral no trabalho nessa categoria. Assim, o enfoque principal deste trabalho é expor e discutir, quantitativamente, a freqüência de ocorrência de situações constrangedoras no trabalho em uma amostra de bancários brasileiros que, dependendo da sua duração e de outros componentes, podem ser compreendidos como assédio moral do trabalho.

Um segundo objetivo foi verificar se o assédio moral, estimado por meio de relatos de ocorrência de situações constrangedoras, tem alguma relação com as características pessoais das vítimas, tais como sexo, idade, escolaridade, raça/etnia, orientação sexual e estado civil.

\section{Método}

\section{População e Amostra}

Participaram do estudo 2609 bancários de 27 bancos diferentes, de 25 dos 27 Estados da Federação (incluindo o Distrito Federal). Essa amostra corresponde a 0,66\% da população total de bancários que totaliza 402.977 trabalhadores, segundo dados da Federação Nacional dos Bancos ([FENABAN], 2006) referentes ao ano de 2005. As principais características da população e da amostra estudada podem ser vistas na Tabela 1. A idade média dos participantes foi de 35,75 anos ( $D P=9,11, n=1722)$. A idade mínima foi de 18 e a máxima de 59 anos.

\section{Questionário}

A coleta de dados foi realizada a través de um questionário fechado contendo questões sócio-demográficas; sobre a ocorrência de 20 possíveis situações de constrangimento no trabalho; uma estimativa da freqüência e duração dos acontecimentos; e, finalmente, questões sobre as características dos agressores. O questionário foi ba-

Tabela 1. Características da População e Amostra Estudada.

\begin{tabular}{|c|c|c|c|}
\hline Variável & Categorias/Níveis & $\begin{array}{l}\text { População } \\
\text { N=402977 }\end{array}$ & $\begin{array}{c}\text { Amostra } \\
\mathrm{n}=2609(0.66 \%)\end{array}$ \\
\hline \multirow{2}{*}{ Sexo } & Homens & $53.5 \%$ & $51.9 \%$ \\
\hline & Mulheres & $46.5 \%$ & $48.1 \%$ \\
\hline \multirow{5}{*}{ Idade } & 16 a 17 anos & $0.2 \%$ & $0 \%$ \\
\hline & 18 a 25 anos & $15.7 \%$ & $16.0 \%$ \\
\hline & 26 a 35 anos & $30.3 \%$ & $33.4 \%$ \\
\hline & 36 a 45 anos & $32.8 \%$ & $32.9 \%$ \\
\hline & Acima de 46 anos & $21.0 \%$ & $17.6 \%$ \\
\hline \multirow{4}{*}{ Escolaridade } & Básico (completo ou incompleto) & $2.2 \%$ & $2.6 \%$ \\
\hline & Médio e profissional (completo ou incompleto) & $43.1 \%$ & $40.9 \%$ \\
\hline & Superior completo & $41,4 \%$ & $44.5 \%$ \\
\hline & Pós-graduação & $8.1 \%$ & $12.0 \%$ \\
\hline \multirow{4}{*}{ Raça/Etnia } & Brancos & $84.4 \%$ & $73.4 \%$ \\
\hline & Negros (pretos e pardos) & $9.2 \%$ & $23.9 \%$ \\
\hline & Amarelos & $2.4 \%$ & $2.3 \%$ \\
\hline & Indígenas & $0.2 \%$ & $0.4 \%$ \\
\hline \multirow{2}{*}{ Orientação Sexual } & Homo e bissexuais & & $2.5 \%$ \\
\hline & Heterossexuais & & $97.5 \%$ \\
\hline \multirow{3}{*}{ Estado Civil } & Solteiros & & $37.0 \%$ \\
\hline & Casados ou Parceiros & & $54.1 \%$ \\
\hline & Separados, divorciados ou viúvos & & $8.9 \%$ \\
\hline
\end{tabular}


seado no instrumento divulgado por Barreto (2005), uma tradução livre do questionário proposto por Hirigoyen (2005). Na parte inicial do questionário além dos dados sócio-demográficos perguntava-se também o nome e o código do banco em que os participantes trabalhavam, as iniciais e a data de nascimento. Estas quatro últimas informações permitiram uma verificação da duplicação de dados. Os casos considerados duplicados: mesmo banco, mesmas iniciais e mesma data de nascimento, foram eliminados da amostra.

\section{Procedimento}

A coleta de dados foi realizada em parte pela Internet e em parte através dos sindicatos da categoria. O questionário foi disponibilizado em um site específico para que o participante pudesse respondê-lo. Os bancários foram instados a participar através de $e$-mails e divulgação da realização da pesquisa pelos seus meios de divulgação: jornais, encartes, cartazes, etc. Ao acessar o site correspondente, era apresentado ao bancário um texto explicativo sobre a pesquisa e seus objetivos, bem como lhe era assegurado o anonimato e solicitada sua adesão voluntária. Se o bancário estivesse de acordo, ele acionava o botão "de acordo" que o levava para a tela contendo o questionário. Os dados recebidos pela Internet foram automaticamente computados em tabelas do programa Excell e essas mesmas tabelas foram complementadas pelos dados dos questionários aplicados pelos sindicatos.

Os dados foram analisados com o auxílio do programa SPSS para Windows (versão 9) e foram comparados através de testes de Qui-quadrado $\left(\chi^{2}\right)$ e análises de variância (ANOVA) mantendo-se o nível de significância de 5\%.

\section{Resultados}

\section{Situações Constrangedoras}

$38,9 \%$ dos bancários da amostra relataram ter passado por uma ou mais situações constrangedoras no trabalho. A Figura 1 mostra a porcentagem de respostas em relação ao total de participantes $(n=2609)$ para cada uma das 20 possíveis situações de constrangimento no trabalho apresentadas no questionário. A situação que ocorre com maior freqüência é "Seu chefe o enche de trabalho", seguida da constatação de que o "Seu chefe prejudica a saúde" e de que "Seu chefe dá instruções confusas e imprecisas".

Considerando-se a série de 20 situações como um índice de assédio, obtém-se um coeficiente de confiabilidade de 0,859 (Alfa de Cronbach). Em média, foram relatadas 1,347 ( $D P=2,603)$ situações constrangedoras. As médias do índice de assédio foram comparadas por análise de variância, verificando-se os efeitos principais de sexo, idade, escolaridade, raça/etnia, orientação sexual e estado civil (Tabela 2). Apenas as diferenças entre as médias de relatos por gênero e orientação sexual apresentaram diferenças significativas.

A média de relatos das mulheres $(1,416)$ foi mais elevada que a dos homens $(1,258)$. Quando se compara a frequiência de relatos em cada uma das 20 situações, as bancárias relatam significativamente mais situações do tipo "Seu chefe não lhe dá qualquer ocupação; não lhe passa as tarefas" $\left(\chi^{2}=8,751 ; \mathrm{gl}=1 ; p=.003\right) \mathrm{e}$ "Seu chefe insinua e faz correr o boato de que você está com problema mental ou familiar" $\left(\chi^{2}=12,286 ; \mathrm{gl}=1 ; p=.000\right)$.

Os homossexuais e bissexuais, considerados conjuntamente, relatam, em média, um maior número de situações (2,16 contra 1,32 dos heterossexuais). As situações em que os homo e bissexuais diferiram dos heterossexuais são mostradas na Tabela 3.

\section{Duração e Freqüência das Agressões}

Dos 1015 bancários que relataram ter vivenciado pelo menos uma situação constrangedora, 369 responderam a questão sobre a duração das agressões. A duração média relatada foi de 11,13 meses $(D P=10,31)$. O número de situações vivenciadas se correlaciona positivamente com a duração das agressões (Índice de correlação de Spear$\operatorname{man}=.217 ; p=.000)$. Isto significa que quanto maior o número de situações vivenciadas, maior é a duração das agressões.

Dos 369 que indicaram a duração das agressões, 260 relataram que as situações de constrangimento tiveram uma duração de pelo menos seis meses, o que corresponde a $9,97 \%$ do total da amostra.

A Tabela 4 mostra a freqüência e porcentagem de respostas sobre a freqüência das agressões para os 260 bancários que relataram vivenciar as situações por seis meses ou mais. Desses, 208 bancários (7,97\% do total da amostra) satisfazem a condição de terem sido agredidos com uma freqüência de pelo menos uma vez por semana.

\section{Perfil dos Agressores e Intencionalidade}

Dos 1508 bancários que responderam à questão sobre terem sido agredidos por outras pessoas além do chefe, $18,50 \%$ responderam positivamente. Das 665 pessoas que responderam à questão "por quantas outras pessoas é agredido?", 59,55\% dizem terem sido agredidos por "uma pessoa", $33,83 \%$ por "de 2 a 4 pessoas" e $6,62 \%$ por "mais de 4 pessoas". Existe uma relação entre o número de situações relatadas e a duração da agressão por ser/não ser agredido por outras pessoas além do chefe (Figuras 2 e 3 , respectivamente) $(F=134,512 ; \mathrm{gl}=1 ; p=.000$ e $F=7,361$, $\mathrm{gl}=1, p=.007)$. Quanto maior o número de agressões e quanto maior a sua duração, a probabilidade dessas agressões se originarem de outras pessoas além do chefe aumenta.

Do mesmo modo, há uma diferença significativa entre as médias das categorias de respostas à pergunta "por 
Maciel, R.H.; Cavalcante, R.; Matos, T.G.R.; Rodrigues, S. "Auto relato de situações constrangedoras no trabalho e assédio moral..." $=$

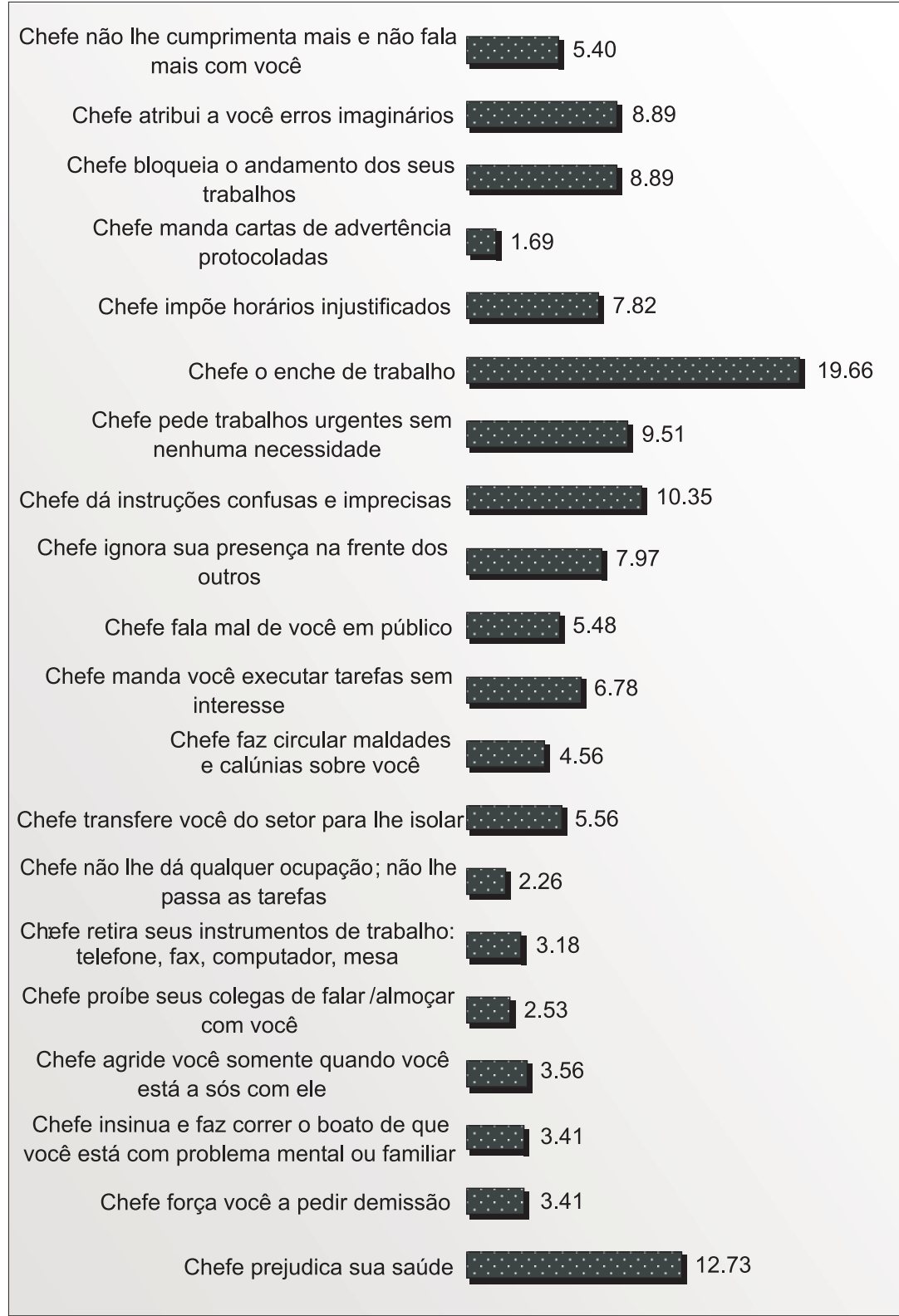

Figura 1. Porcentagem de respostas a cada uma das situações constrangedoras propostas no questionário $(n=2609)$.

Tabela 2. Resultados da Análise de Variância (ANOVA) do Índice de Assédio (somatória do número de situações constrangedoras relatadas.

\begin{tabular}{lcccc}
\hline \multicolumn{1}{c}{ Fonte } & $\begin{array}{c}\text { Soma dos } \\
\text { Quadrados }\end{array}$ & gl & F & Sig. \\
\hline Sexo & 35.2130 & 1 & 4.8389 & 0.0280 \\
Faixa etária & 43.6484 & 3 & 1.9994 & 0.1122 \\
Escolaridade & 33.0924 & 3 & 1.5158 & 0.2086 \\
Raça/etnia & 35.9344 & 3 & 1.6460 & 0.1769 \\
Orientação sexual & 41.8814 & 1 & 5.7553 & 0.0166 \\
Estado Civil & 26.4304 & 2 & 1.8160 & 0.1631 \\
\hline
\end{tabular}


Tabela 3. Resultados dos Testes de $\chi^{2}$ dos Cruzamentos entre os Grupos

"Heterossexuais"e "Homo e Bissexuais" e as 20 Situações Constrangedoras.

\begin{tabular}{lccc}
\hline $\begin{array}{l}\text { Situação Constrangedora } \\
\text { "Seu chefe" }\end{array}$ & $\chi^{2}$ & gl & p \\
\hline Seu chefe ignora sua presença na frente dos outros & 14,485 & 1 & .000 \\
Seu chefe manda você executar tarefas sem interesse & 8,012 & 1 & .005 \\
Seu chefe agride você quando você está a sós com ele & 16,304 & 1 & .000 \\
Seu chefe força você a pedir demissão & 7,349 & 1 & .007 \\
\hline
\end{tabular}

Tabela 4. Distribuição das Respostas quanto à Freqüência das Agressões entre aqueles que Declararam terem sido Agredidos por Seis Meses ou Mais.

\begin{tabular}{lccc}
\hline \multicolumn{1}{c}{ Categorias } & Freqüência & Porcentagem & Porcentagem Válida \\
\hline uma vez por mês & 43 & 16.5 & 17.1 \\
uma vez por semana & 61 & 23.5 & 24.3 \\
várias vezes por semana & 147 & 56.5 & 58.6 \\
Total & 251 & 96.5 & 100.0 \\
NR & 9 & 3.5 & \\
Total & 260 & 100.0 & \\
\hline
\end{tabular}

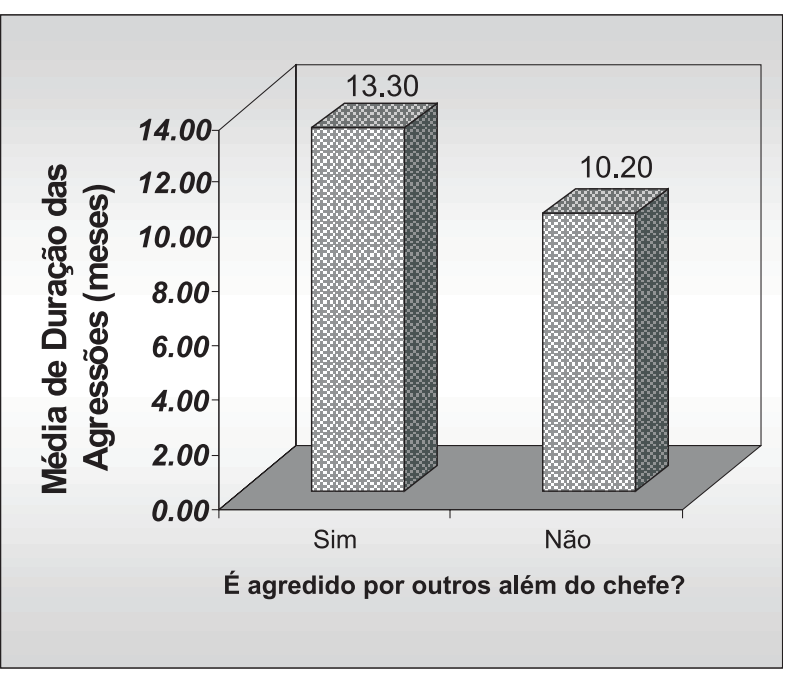

Figura 2. Média do número de situações relatadas por ser agredido por outras pessoas além do chefe $(n=1508)$.

quantas pessoas é agredido" e o número de situações relatadas, bem como a duração das agressões (Figuras 4 e 5) $(F=4,936 ; \mathrm{gl}=2 ; p=.007$ e $F=10,812 ; \mathrm{gl}=2 ; p=.000$, respectivamente). Quanto maior o número de situações relatadas e quanto maior a duração média das agressões, maior o número de pessoas que agridem.

Dos 733 participantes que responderam a questão sobre a posição do agressor na hierarquia, a maioria $(63,71 \%)$ identifica o superior hierárquico como agressor, mas tam-

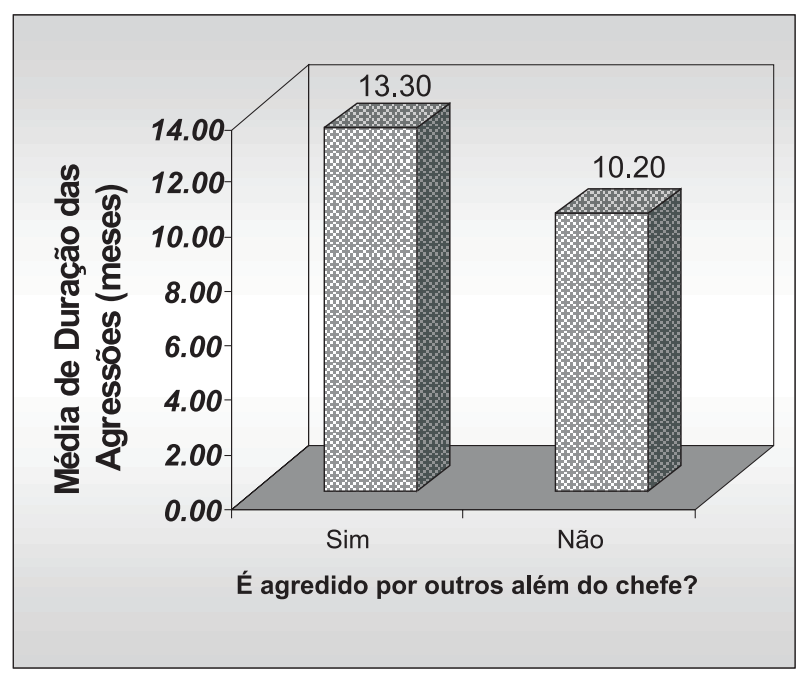

Figura 3. Média da duração das agressões por ser agredido por outras pessoas além do chefe $(n=363)$.

bém foram relatadas agressões por parte de colegas. Além disso, o agressor é apontado mais vezes como sendo do sexo masculino $(50,96 \%)$.

Os participantes homo e bissexuais identificam o conjunto de colegas como agressores com uma maior frequiência do que os heterossexuais $\left(\chi^{2}=8,717, \mathrm{gl}=1, p=.003\right)$ (Figura 6).

Os bancários com nível de escolaridade básico tendem a identificar os subordinados como agressores com 
uma frequiência maior que os bancários de outros níveis de escolaridade $\left(\chi^{2}=15,670, \mathrm{gl}=4, p=.003\right)$ (Figura 7).

As mulheres tendem a apontar as mulheres como agressoras com maior frequiência que os homens, como mostra a Figura $8\left(\chi^{2}=29,143, \mathrm{gl}=3, p=.000\right)$.

A Tabela 5 mostra a distribuição das respostas sobre o tipo de agressor e os resultados dos testes de $\chi^{2}$. Somente quando o agressor é identificado como sendo o superior hierárquico há uma maior frequiência de identificação de homens como agressores, em todos os outros casos, as mulheres são apontadas com maior freqüência como agressoras.

Dos 848 bancários que responderam à questão sobre a consciência do agressor ("Você acha que o agressor tem consciência do que faz?'), 49,41\% responderam afirmativamente, $17,10 \%$ negativamente e $33,49 \%$ afirmaram não saber. Quando o agressor é o superior hierárquico, há

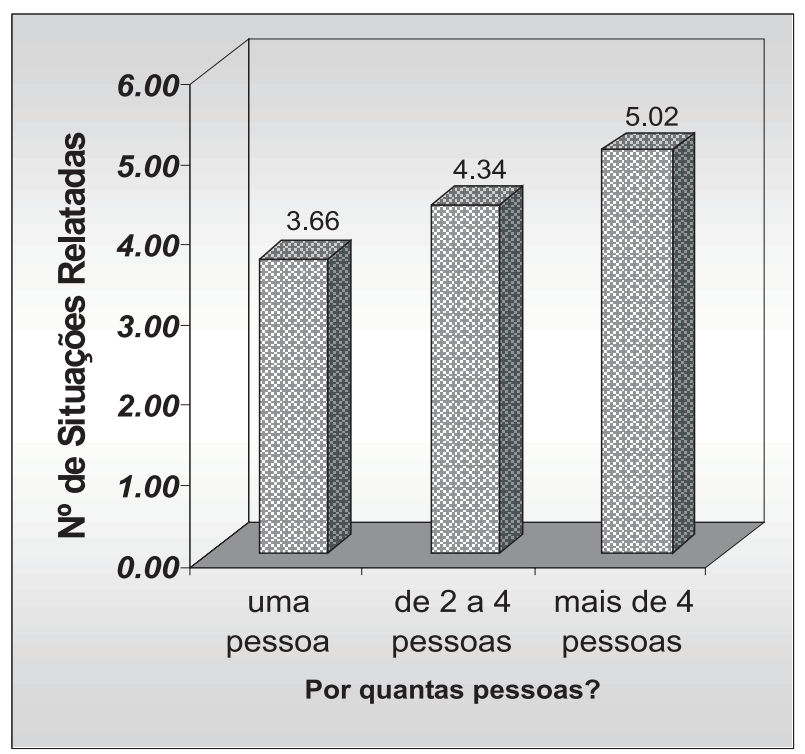

Figura 4. Média do número de situações relatadas pelo número de pessoas que agridem(a) $(n=301)$.

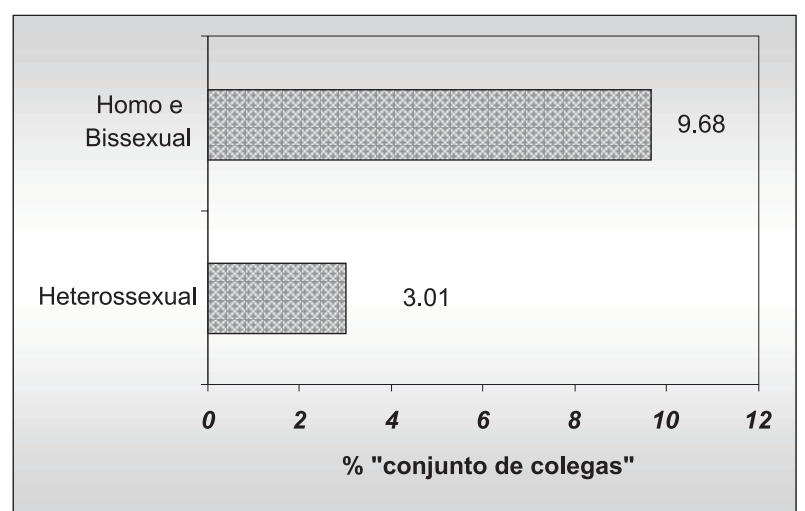

Figura 6. Porcentagem das respostas ao tipo de agressor "conjunto de colegas" por orientação sexual ( $n=2484)$. uma tendência a se acreditar, com uma maior freqüência, que ele sabe o que faz $\left(\chi^{2}=13,428 ; \mathrm{gl}=2 ; p=.001\right)$.

\section{Discussão e Conclusões}

Os resultados da pesquisa mostraram que $33,89 \%$ da amostra relata ter sido exposta a pelo menos uma das situações constrangedoras no trabalho. Esse resultado se aproxima da cifra encontrada por Barreto (2003a, 2003b) em uma outra amostra de trabalhadores brasileiros. Entre as variáveis sócio-demográficas estudadas apenas o gênero e a orientação sexual da vítima levam a diferenças no índice de assédio, sendo que as mulheres e o grupo de homo e bissexuais relatam terem passado por um maior número de situações constrangedoras. No entanto, as duas situações em que homens e mulheres diferem se referem à categoria de assédio pessoal em contraposição à categoria de assédio organizacional, como classificado por Bes-

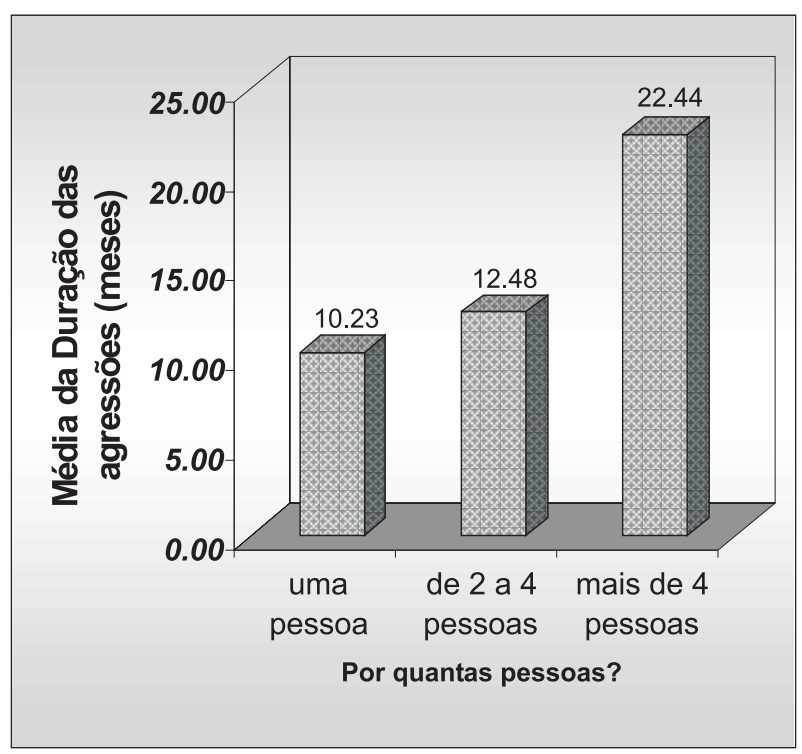

Figura 5. Média da duração da agressão pelo número de pessoas que agridem $(n=665)$.

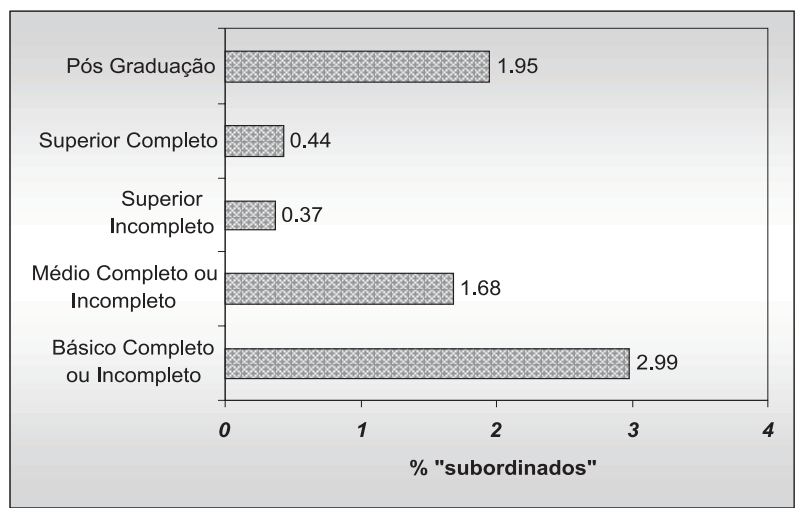

Figura 7. Porcentagem das respostas ao tipo de agressor "subordinado" por escolaridade $(n=2569)$. 


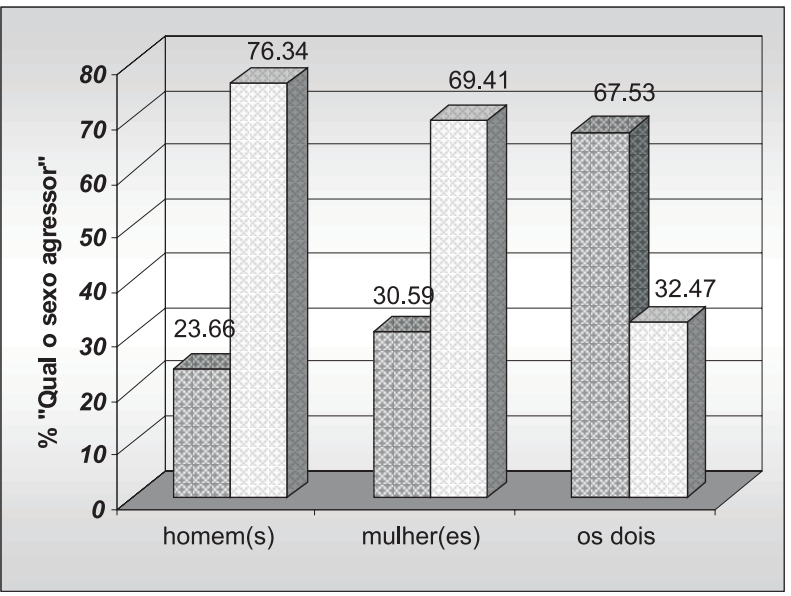

Figura 8. Porcentagem das respostas sobre o tipo de agressor por sexo $(n=760)$.

wick et al. (2006). Além disso, este resultado confirma a idéia de Einarsen (2005) de que o assédio ocorre "em cascata". No modelo proposto pelo autor, o assédio pessoal carregado dos preconceitos sociais, aparece acoplado ao assédio organizacional, somando-se a ele, daí o fato das mulheres e o grupo de homo e bissexuais relatarem serem mais assediados que os homens e os heterossexuais, respectivamente, exatamente nas situações que denotam assédio pessoal, mas não diferem nas situações com conotação organizacional.

Quando se considera apenas o relato de situações constrangedoras que perduraram por seis meses e ocorreram com uma frequiência semanal, a porcentagem de bancários assediados na nossa amostra é de 7,97\%, uma prevalência igual ou mais baixa do que a encontrada em amostras européias, como por exemplo, as encontradas por Hoel et al. (2001b) e Vartia (1996), de aproximadamente 10\%.É bem provável que as condições atuais de trabalho da categoria bancária brasileira e as condições de trabalho na Europa difiram consideravelmente, sendo que é bem possível que as condições brasileiras, dadas as limitações socioeconômicas, sejam piores. Assim, a cifra encontrada surpreende. Uma possibilidade que pode explicar esse resultado diz respeito ao instrumento utilizado e seu entendimento por parte dos participantes, bem como às questões culturais associadas a esse entendimento. Um traço cultural apontado nos estudos da cultural organizacional de instituições brasileiras é que os trabalhadores tendem a apresentar uma postura submissa nas relações de trabalho com os superiores hierárquicos (Prates \& Barros, 1997). Esse traço pode ser tão inflexível que impeça o relato das situações constrangedoras ou amenize a percepção de sua importância e gravidade. De qualquer forma, essa hipótese teria que ser verificada em outros estudos que ampliem o questionário aplicado ou que se utilizem métodos qualitativos para identificar traços culturais na percepção do assédio moral. Apesar disso, se considerarmos a categoria bancária como um todo, cerca de 32.000 pessoas devem ter sido assediadas nos últimos seis meses com uma freqüência semanal.

Salin (2005) explica que em algumas profissões e organizações os comportamentos negativos são esperados como parte da cultura e, portanto, não são considerados como assédio. Assim, é possível que algumas das situações constrangedoras aqui descritas, não sejam percebidas como agressão por fazerem parte da cultura organizacional bancária. Einarsen e Skogstad (1996) atentam para a importância de se diferenciar entre comportamentos negativos que são tolerados e comportamentos que não são tolerados, bem como entre situações que podem ser administradas e situações onde as vítimas têm dificuldade para se defenderem. Um estudo mais aprofundado sobre como os bancários percebem os diferentes tipos de situações constrangedoras pode ser produtivo para uma melhor compreensão do assédio moral na sua relação com os componentes culturais da organização.

Com relação às diferenças de gênero, mais mulheres relataram ter vivenciado situações constrangedoras do que os homens. Enquanto os homens evidenciaram mais situações de assédio organizacional, as mulheres ressaltaram maior freqüência daquelas relacionadas ao assédio pessoal. Este resultado está em consonância com outros estudos já realizados que indicam que o assédio moral é maior em mulheres do que em homens (Jiménez, Muñoz, Hernández, Benadero \& Carvajal, 2005; Salin, 2005), indicando que o fato de ser mulher parece ser um risco adicional para a ocorrência do assédio. Jiménez et al.

Tabela 5. Porcentagem das Respostas sobre o Tipo de Agressor $(n=781)$.

\begin{tabular}{lccccc}
\hline & $\begin{array}{c}\text { Homem(s) } \\
(\%)\end{array}$ & $\begin{array}{c}\text { Mulher(es) } \\
(\%)\end{array}$ & $\begin{array}{c}\text { Os dois } \\
(\%)\end{array}$ & $\begin{array}{c}\chi^{2} \\
(\mathbf{g l}=\mathbf{2})\end{array}$ & $\boldsymbol{p}$ \\
\hline Colega & 13.07 & 23.60 & 16.10 & 10.021 & 0.007 \\
Conjunto de colegas & 3.52 & 4.49 & 27.80 & 95.795 & 0.000 \\
Superior hierárquico & 64.32 & 56.74 & 48.78 & 13.761 & 0.001 \\
Subordinado & 0.75 & 3.37 & 6.34 & 5.149 & 0.076 \\
Conjunto de subordinados & 0.75 & 0.56 & 6.34 & 15.690 & 0.000 \\
\hline
\end{tabular}


(2005), em um estudo semelhante ao nosso, chamam a atenção para o fato de que o grupo masculino tende a relacionar os fatores organizacionais ao assédio moral, enquanto que o grupo feminino relaciona o assédio a fatores pessoais. É importante considerar ainda que os aspectos sócio-culturais têm um importante papel na forma como homens e mulheres percebem as situações no trabalho, sendo possível que os homens se sintam ameaçados por circunstâncias de cunho mais geral relacionados à competitividade e desempenho no trabalho, enquanto que as mulheres sejam mais sensíveis aos conflitos de relacionamento pessoal.

Os resultados mostram também que a orientação sexual é um fator de discriminação, além do gênero, perpassando as relações de trabalho, e se somando ao assédio organizacional. Desta forma, configura-se o caráter amplo do assédio moral ao abranger diferentes comportamentos que variam segundo o contexto social, cultural e organizacional.

Os resultados mostraram também que quanto maior o número de situações relatadas, maior a duração média das agressões e maior a probabilidade da vítima ter sido agredida por mais de uma pessoa além do chefe. No entanto, a grande maioria relata ter sido agredida pelo superior hierárquico, um indicativo de que o assédio na categoria é do tipo organizacional. Outra explicação possível para esse resultado se relaciona à estrutura da organização e ao desequilíbrio das relações de poder. As organizações brasileiras apresentam uma grande distância de poder, o que implica em desigualdade e distância hierárquica. Freitas (1997) ao analisar a cultura organizacional brasileira aponta a hierarquia como um traço forte que se revela pela centralização do poder, distanciamento nas relações entre diferentes grupos sociais, e passividade e aceitação dos grupos inferiores. Um dos fatores descritivos do assédio é o desequilíbrio de poder e a incapacidade da vítima em defender-se das agressões, o que torna bastante favorável seu acontecimento em condições onde as relações hierárquicas autoritárias são ressaltadas. Desta forma, a ênfase em estilos de liderança autocráticos parece ser um indicativo propício para a ocorrência do assédio moral, o que deveria ser investigado em um outro estudo.

Além disso, os homens em posição de chefia costumam ser os agressores, enquanto as mulheres são apontadas como agressoras, com maior freqüência, quando ocupam outras posições na organização. Uma explicação possível é que os homens com maior freqüência do que as mulheres estão em posições superiores, o que facilita serem apontados como agressores. Outros estudos (Einarsen \& Skogstad, 1996; Hoel et al., 2001b) também mostram que os homens tendem a ser assediados por homens e as mulheres por mulheres.

Este estudo mostra que o assédio moral entre bancários, quando confrontado com aspectos sócio-demográficos, faz surgir uma complexa rede de influências, onde os fatores sociais, como gênero, idade e orientação sexual, ao interagirem com características organizacionais, como a posição hierárquica, podem propiciar o surgimento do assédio como um processo "em cascata", que se intensifica de forma gradual. Isto reforça a idéia de um ciclo vicioso, cuja causa e efeito só poderão ser determinados quando analisados de forma mais profunda, incluindo outros fatores do meio ambiente de trabalho relacionados ao assédio moral e a cultura local.

\section{Notas}

1 Pesquisa realizada dentro do projeto da CONTRAF (Confederação dos Sindicatos de Trabalhadores de Instituições Financeiras, ex-CNBCUT) “Assédio moral na categoria bancaria: Uma experiência no Brasil", com o apoio financeiro do FIG (Fundo para Igualdade de Gênero) e CIDA (Agência de Desenvolvimento do Governo do Canadá). Participaram como colaboradores: Luís Saraiva Neves, Andréa da Hora, Francisco Gonzaga Bitu, Teresa Cristina F. de Souza

\section{Referências}

Barreto, M. (2003a). Assédio moral: Suas ocorrências e conseqüiencias. Fortaleza, CE: Sindicato dos Bancários do Ceará.

Barreto, M. (2003b). Violência, saúde e trabalho (uma jornada de humilhações). São Paulo, SP: EDUC.

Barreto, M. (2005). Questionário sobre assédio moral. Retirado em out. 2005, de http://www.assediomoral.org/site/assedio/ question.php

Beswick, J., Gore, J., \& Palferman, D. (2006). Bullying at work: A review of the literature. Health and Safety Laboratory. Working Paper Series, 6(4). Retirado em jun. 2006, de www.hse.gov.uk/ research/hsl_pdf/2006/hs10630.pdf

Bjorkqvist, K. (2001). Social defeat as a stressor in humans. Psychology \& Behavior, 73, 435-442.

Bolino, M. C., \& Turnley, W.H. (2003). Counternormative impression management, likeability, and perfomance ratings: The use of intimidation in an organizational setting. Journal of Organizational Behavior, 24, 237-250.

Bullying. (2006). Bullying on line. Retirado em jun. 2006, de http:// www.bullyonline.org/workbully/mobbing.htm

Buskpan, E. (2004). Bullying at work in France: A personal view. British Journal of Guidance \& Counselling, 32(3), 397-406.

Cowie, H., Naylor, P., Rivers, I., Smith, P. K., \& Pereira, B. (2002). Measuring workplace bullying. Agression and Violent Beavior, 7, 33-51.

Coyne, I., Craig, J., \& Chong, P. S-L. (2004). Workplace bullying in a group context. British Journal of Guidance \& Counselling, 32(3), 301-317.

Crothers, L. M., \& Levinson, E. M. (2004). Assessment of bullying: A review of methods and instruments. Journal of Counseling \& Development, 82(4), 496-503.

Dick, G., \& Rayner, C. (2004). Exploring the workplace bullying construct: An evidence-based approach. Kent, UK: Canterbury Business School. Retirado em jun. 2006, de http://www.kent.ac.uk/ kbs/research-information/working-papers/Gavin-Dick-No51.pdf 
Einarsen, S. (2005). The nature, causes and consequences of bullying at work: The Norwegian experience. Pistes, 7(3). Retirado em jun. 2006, dehttp://www.pistes.uqam.ca/v7n3/articles/v7n3alen.htm

Einarsen, S., Bjorn, I. R., \& Matthiesen, S. B. (1994). Bullying and harassment at work and their relationships to work environment quality: An exploratory study. European Journal of Work and Organizational Psychology, 4(4), 381-401.

Einarsen, S., \& Hoel, H. (2001). The Negative Acts Questionnaire: Development, validation and revision of a measure of bullying at work. In Proceedings of the 10th. European Congress on Work and Organisational Psychology: Globalization-Opportunities and Threats. Prague, Czech Republic.

Einarsen, S., \& Skogstad, A. (1996). Bullying at work: Epidemiological findings in public and private organizations. European Journal of Work and Organizational Psychology, 5(2), 185-201.

Federação Nacional dos Bancos. (2006). Dados do Setor. Colaboradores. Retirado em mar. 2006, de http://www.fenaban.org.br/ Arquivo/Servicos/Dadosdosetor/Colaboradores_2005_dadossetor. asp

Fonseca, Z. A., Filho (2006, maio). As relações públicas e pensamento habermasiana como instrumento para a crise da contemporaneidade. In XI Simpósio de Ciências da Comunicação na Região Sudeste. Ribeirão Preto, SP: Sociedade Brasileira de Estudos Interdisciplinares da Comunicação. Retirado em dez. 2006, de http://reposcom.portcom.intercom.org.br/items-by-author? author=Fonseca+Filho\%2C+Zadoque+Alves+da

Freitas, M. E. (1997). Cultura organizacional: O doce controle no clube dos raros. In F. P. Motta \& M. P. Caldas (Eds.), Cultura organizacional e cultura brasileira. São Paulo, SP: Atlas.

Grisci, C. L. I. (2002). Reestruturação do trabalho bancários: Velocidade e sofrimento psíquico. SOCIUS Working Papers, 4. Retirado em mar. 2006, de http://pascal.iseg.utl.pt/ socius/ index.htm

Grisci, C. L. I., \& Bessi, V. G. (2004). Modos de trabalhar e de ser na reestruturação bancária. Sociologias (Porto Alegre), 6(12), 160-200.

Hansen, A. M., Hogh, A., Persson, R., Karlson, B., Garde, A. H., \& Orbak, P. (2006). Bullying at work, health outcomes, and physiological stress response. Journal of Psychosomatic Research, 60, 63-72.

Hirigoyen, M. F. (2005). Questionnaire sur lê Harcelement Moral. Retirado em out. 2005, de http://hirigoyen.free.fr/ questionnaire.pdf

Hoel, H., Sparks, K., \& Cooper, C. L. (2001a). The cost of violence/ stress at work and the benefits of a violence/stress-free working environment (Report commissioned by the International Labour Organisation, conducted by University of Manchester Institute of Science and Technology). Retirado em jun. 2006, de http:// www.ilo.org/public/english/protection/safework/whpwb/econo/ costs.pdf

Hoel, H., Cooper, C. L., \& Faraguer, B. (2001b). The experience of bullying in Great Britain: The impact of organizational status. European Journal of Work and Organizational Psychology, 10(4), 443-465.

Hoel, H., Faragher, B., \& Cooper, C. L. (2004). Bullying is detrimental to health, but all bullying behaviours are not necessarily equally damaging. British Journal of Guidance \& Counselling, 32(3), 367-387.

Health and Safety Authority. (2001). Dignity at work - The challenge of workplace bullying (Report of the Taskforce on the Prevention of Workplace Bullying). Dublin, UK: The Stationary Office.
Retirado em jun. 2006, de http://www.entemp.ie/publications/ employment/2005/bullyingtaskforce.pdf

Jiménez, B. M., Muñoz, A. R., Hernández, E. G., Benadero, M. E. M., \& Carvajal, R. R. (2005). Diferencias de gênero en el acoso psicológico en el trabajo: un estudio en población española. Psicologia em Estudo, 10(1), 3-10.

Laranjeira, S. M. G. (1997). Reestruturação produtiva no setor bancário: A realidade dos anos 90. Educação \& Sociedade, 18(61), 110-138.

Laranjeira, S. M. G. (2001). Reestruturação em bancos e telecomunicações no Brasil: Excluídos e beneficiados. In R. Aguirre \& Batthyány, K. (Ed.), Trabajo, Género y Ciudadanía en los Países del Cono Sur (pp. 111-132). Retirado em mar. 2006, de http:// www.ilo.org/public/spanish/region/ampro/cinterfor/publ/gen_sur/ index.htm

Lewis, M. A. (2004). Will the real bully please stand up. Journal of Occupational Health, 56(5), 22-28.

Leymann, H. (1996). The content and development of mobbing at work. European Journal of Work and Organizational Psychology, 5(2), 165-184.

Leymann, H. (2006). Mobbing concept. The Mobbing Encyclopedia. Retirado em jun. 2006, de http://www.bullyonline.org/workbully/ mobbing.htm

Leymann, H., \& Gustafsson, A. (1996). Mobbing at work and the development of pos-traumatic stress disorders. European Journal of Work and Organizational Psychology, 5(2), 251-275.

Liefooghe, A. P. D. (2004). Bullying at work: An introduction to the symposium. British Journal of Guidance \& Counselling, 32(3), 265-267.

Liefooghe, A. D., \& Davey, K. M. (2001). Accounts of workplace bullying: The role of the organization. European Journal of Work and Organizational Psychology, 10(4), 375-392.

Liefooghe, A. P. D., \& Olafsson, R. (1999). "Scientists" and "amateurs": Mapping the bullying domain. International Journal of Manpower, 20(1/2), 39-49.

Lima, W. S., \& Maciel, R. H. (2001). A percepção dos caixas estatais sobre as mudanças no seu trabalho. In R. Rigotto (Ed.), As tramas da (in)sustentabilidade: Trabalho, meio ambiente e saúde no Ceará. Fortaleza, CE: INESP.

Maciel, R. H. (2000a). Pesquisa sobre condições de trabalho e qualidade de vida dos bancários da grande Fortaleza, Ceará. Fortaleza, CE: Sindicato dos Bancários do Ceará.

Maciel, R. H. (200b). A picture of Bank Employees of Fortaleza: Health and quality of life. In Proceedings of the XIVth Triennial Congress of the International Ergonomics Association, Santa Monica: Human Factors and Ergonomics Society, 6, 168-171.

Matthiesen, S. B., \& Einarsen, S. (2001). MMPI2 configurations among victims of bullying at work. European Journal of Work and Organizational Psychology, 10 (4), 467-484.

Matthiesen, S. B., \& Einarsen, S. (2004). Psychiatric distress and symptoms of PSTD among victims of bullying at work. British Journal of Guidance \& Counselling, 32(3), 335-356.

Mikkelsen, E., \& Einarsen, S. (2001) Bullying in Danish work-life: Prevalence and health correlates. European Journal of Work and Organizational Psychology, 10(4), 393-413.

Mobbing.Nu. (2006). Mobbing. Retirado em jun. 2006, de http:// www.mobbing.nu

Monteiro, J. K., Espírito Santo, F. C., \& Bonacina, F. (2005). Valores, ética e julgamento moral: Um estudo exploratório em empresas familiares. Psicologia: Reflexão e Crítica, 18(2), 237-246. 
Nansel, T. R., Overpeck, M., Pilla, R.S., Ruan, J., Simons-Morton, B., \& Scheidt, P. (2001). Bullying behaviors among US youth: Prevalence and association with psychosocial adjustment. Journal of the American Medical Association, 285, 2094-2100.

Natvig, G. K., Albrektsen, G., \& Qvarnstrom, U. (2001). Schoolrelated stress experience as a risk factor for bullying behavior. Journal of Youth and Adolescence, 30(5), 561-575.

Organizacion Internacional del Trabajo. (1998). Cuando el trabajo resulta peligroso. Trabajo, Revista de la OIT, 26. Retirado em out. 2005, de http://www.ilo.org/public/spanish/bureau/inf/magazine/26/violence.htm

Olafsson, R. F., \& Johannsdottir, H. L. (2004). Cooping with bullying in the workplace: The effect of gender, age and type of bullying. British Journal of Guidance \& Counselling, 32(3), 319-333.

Paoli, P., \& Merllié, D. (2001). Third European Survey on Working Conditions 2000. Luxembourg, Belgique: Office for Official Publications of the European Communities. Retirado em jun. 2006, de http://www.eurofound.eu.int/pubdocs/2001/21/en/1/ef0121en. pdf

Prates, M. A. S., \& Barros, B. T. (1997). O estilo brasileiro de administrar: Sumário de um modelo de ação cultural brasileiro com base na gestão empresarial. In F. C. P. Motta \& M. P. Caldas (Eds.), Cultura organizacional e cultura brasileira. São Paulo, SP: Atlas.

Quine, L. (1999). Workplace bullying in NHS community trust: Staff questionnaire survey. British Medical Journal, 318(23), 228-232.

Quine, L. (2002). Workplace bullying in junior doctors: Questionnaire survey. British Medical Journal, 324, 878-879.

Rego, A. (2002). Climas éticos e comportamentos de cidadania organizacional. RAE - Revista de Administração de Empresas, 42(1), 50-63.

Salin, D. (2005). Workplace bullying among business professionals: Prevalence, gender differences and the role of organizational politics. Pistes, 7(3). Retirado em jun. 2006, de http://www.pistes. uqam.ca/v7n3/articles/v7n3a2en.htm

Segnini,L. R. P. (1999). Reestruturação nos bancos no Brasil: Desemprego, subcontratação e intensificação do trabalho. Educação \& Sociedade, 20(67), 183-209.

Sennett, R. (2006). A cultura do novo capitalismo. São Paulo, SP: Record.

Tehrani, N. (2004). Bullying: a source of chronic post-traumatic stress? British journal of Guidance \& Counselling, 32(3), 357-366.
Vartia, M. (1996). The sources of bullying - Psychological work environment and organizational climate. European Journal of Work and Organizational Psychology, 5(2), 203-214.

Zapf, D. (1999). Organisational, work group related and personal causes of mobbing/bullying at work. International Journal of Manpower, 20(1/2), 70-85.

Zylbersztajn, D. (2002). Organização ética: um ensaio sobre comportamento e estrutura das organizações. Revista de Administração Contemporânea, 6(2), 123-143.

Regina Heloisa Maciel é graduada em Psicologia pela Universidade de São Paulo, mestrado em Applied Psychology Ergonomics pela University Of Wales Institute Of Science And Techonology e doutorado em Psicologia (Psicologia Experimental) pela Universidade de São Paulo. Atualmente é professora titular da Universidade de Fortaleza. Endereço para correspondência: Rua Rangel Pestana, 2424,

Fortaleza, CE, 60834-250. Tels.: (085) 32781909, 32731467, 99061959. rhmaciel@ rapix.com.br rhmaciel@fortalnet.com.br

Rosemary Cavalcante é graduada em Psicologia pela Universidade Federal do Ceará, mestre em Psicologia pela Universidade de Fortaleza. Docente na Universidade de Fortaleza.

Teresa Glaucia Rocha Matos, Universidade de Fortaleza.

Suzineide Rodrigues. Vinculada ao Sindicato dos Bancários de Pernambuco.

\section{Auto relato de situações constrangedoras no trabalho e assédio moral nos bancários: uma fotografia}

Regina Heloisa Maciel, Rosemary Cavalcante, Teresa Glaucia Rocha Matos \& Suzineide Rodrigues

Recebido dia: 9/08/2006

$1^{\text {a }}$ revisão: 23/04/2007

Aceite final: 20/06/2007 